\title{
An Investigation on Mechanical Behavior of Tooth-Plate-Glass-Fiber Hybrid Sandwich Beams
}

\author{
Honglei Xie $\mathbb{D}^{1},{ }^{1}$ Li Wan $\left(\mathbb{D},{ }^{1,2}\right.$ Bo Wang, ${ }^{3}$ Haiping Pei $\left(\mathbb{D},{ }^{1}\right.$ Weiqing Liu $\mathbb{D}^{1,2}$ Kong Yue, ${ }^{1,2}$ \\ and Lu Wang (iD) 1,2 \\ ${ }^{1}$ College of Civil Engineering, Nanjing Tech University, Nanjing, China \\ ${ }^{2}$ Advanced Engineering Composites Research Center, Nanjing Tech University, Nanjing, China \\ ${ }^{3}$ Nanjing Metro Construction Co., Ltd., Nanjing, China
}

Correspondence should be addressed to Li Wan; wanli@njtech.edu.cn

Received 16 October 2019; Accepted 14 January 2020; Published 12 February 2020

Guest Editor: Tianyu Xie

Copyright (c) 2020 Honglei Xie et al. This is an open access article distributed under the Creative Commons Attribution License, which permits unrestricted use, distribution, and reproduction in any medium, provided the original work is properly cited.

Tooth-plate-glass-fiber hybrid sandwich (TFS) is a type of sandwich composites fabricated by vacuum-assisted resin infusion process, in which glass fiber facesheets reinforced by metal plate are connected to foam core through tooth nails. Bending properties and interlaminar properties of TFS beams with various foam densities were investigated by flexural tests and DCB (double cantilever beam) tests. The test results showed that by increasing the foam core density from $35 \mathrm{~kg} / \mathrm{m}^{3}$ to $150 \mathrm{~kg} / \mathrm{m}^{3}$, the peak strength of TFS beams significantly increased by $168 \%$ to $258 \%$ compared with similar sandwich beams with fibrous composite facesheets. With the change of foam density and span length, the main failure modes are core shear and facesheet indentation beneath the loading roller. The interlaminar strain energy release rates of TFS specimens also increased by increasing the density of the foam. In addition, an analytical model was used to predict the ultimate bending strength of TFS beams, which were in good accordance with the experimental results.

\section{Introduction}

A composite sandwich structure consists of facesheets and core and has been widely used in structural engineering, marine, and transportation industry [1]. The fiber-reinforced plastics (FRP) or metallic layers are usually used as skin materials. Metal sheets are heavy but have better resistance against impact load. Compared with metal facesheet, with the characteristics of high strength-to-weight ratio and stiffness-to-weight ratio, fiber facesheets have, respectively, lower resistance of local impact. In order to combine the advantages of both structures, fiber metal laminates (FMLs) were created, which built up from interlacing layers of thin metals and fiber-reinforced composite [2]. FMLs have superior specific static properties and excellent damage resistance, including high impact resistance and flame resistance [3-5].

In the past two decades, many researchers have studied the mechanical properties of FMLs under various mechanical loads. Kashani et al. [6] investigated the scaling effects of fiber metal laminates by tensile and three-point bending tests. FMLs were made of aluminum 1050 and unidirectional glassepoxy. The test results showed that scaling has no effect on general tensile behaviors of FMLs. The failure modes of FMLs were fiber breakage, delamination between composite layers, debonding between metal and composite layers, and aluminum fracture in tensile tests. They also found that fiber metal laminates obey scaling law under three-point bending load and the main failure mode was debonding between metal and composite layers.

Steeves and Fleck [7] investigated collapse mechanisms of sandwich beams with composite faces and a foam core under three-point bending load. The results showed that main failure modes are facesheet microbuckling, plastic shear of the core, and facesheet indentation beneath the middle loading roller. The failure mode depends primarily on the geometry of the sandwich beam and the density of foam core. 
Kabir et al. [8] investigated the response of sandwich panels with aluminium facesheets under three-point bending load. They indicated that the failure modes were influenced by the strength of facesheets, foam core thickness, and span length. They found that sandwich panels with very thin aluminium facesheets were generally dominated by indentation failure mode. Face yielding occurred when lowstrength facesheets were used, and core yielding occurred when strong facesheets were used. They also pointed out that a significant increase of the facesheets strength only marginally increases panels' resistance to bending. Meanwhile, theoretical models were proposed to predict the failure loads of each failure mode.

Dariushi and Sadighi [9] studied the bending properties of sandwich beams with fiber metal laminates facesheets and compared them with similar sandwich beams with fibrous composite faces. The results showed that FML faces have better resistance against transverse local loads and minimize stress concentration and local deformations of skin and core under the loading tip. In addition, sandwich beams with FML faces have larger elastic region and absorb more energy. Furthermore, they proposed a geometrical nonlinear theory to predict force-deflection behavior.

Reyes [10] investigated the flexural properties of FML reinforced sandwich panel with aluminum foam core. The test results showed that the use of fiber metal laminates as the skin material can improve the impact behavior, damage resistance, and damage tolerance of sandwich structures. Meanwhile, energy absorption characteristics of the sandwich components were studied, and the proposed energy balance model was in good accordance with the experiment results. Ortiz de Mendibil et al. [11] studied the impact behavior of glass fiberreinforced epoxy/aluminum fiber metal laminate. Fiber metal laminates were manufactured by liquid molding. The test results revealed that the holes located out of the impact zone have no effect in the damage mechanisms. The failure mode of the FMLs was metal dominated. The first delamination appeared between metal and composite layers at $20 \mathrm{~J}$, the first crack in the aluminum layers appeared at $40 \mathrm{~J}$, and afterwards fiber breakage started at $42 \mathrm{~J}$. Reyes Villanueva and Cantwell [12] studied the high velocity impact response of a range of novel aluminum foam sandwich structures with FML skins. The test results revealed that sandwich structures with FML faces have an excellent energy absorption characteristic when subjected to dynamic load. Further studies of the mechanical behavior of glass fiber-reinforced polypropylene FMLs had been conducted by Reyes and Cantwell [13]. They pointed out that the interfacial fracture toughness of FMLs initially increases with the crosshead displacement rate up to $100 \mathrm{~mm} /$ min before reducing again at higher displacement rates. Meanwhile, single cantilever beam tests and low-velocity impact tests were conducted. The test results showed that these materials offer excellent resistance to dynamic load and the incident energy was absorbed through plastic deformation in the aluminum layers and localized microcracking within the composite plies. Srinivasagupta et al. [14] pointed out that the interfacial bonding performance had a great influence on the reliability of sandwich materials with foam core. During the compression, tension, and bending tests, the failure was initiated through the interface. In this paper, the effects of processing conditions and material properties on the interfacial strength of sandwich structures were studied. The test results revealed that the debonding fracture toughness of foam core sandwich composites increased with the increase of the temperature. The compliance derivative method was proposed to evaluate the mode I fracture toughness or the critical fracture energy rate [15]. Vadakke and Carlsson [16] studied the interfacial bonding behavior between the facesheets and the foam core. They concluded that the density of foam core has a great influence on the interfacial bonding strength. Meanwhile, the interfacial bonding strength increased with the increase in the density of foam core.

In this paper, a new type of foam sandwich structure (tooth-plate-glass-fiber hybrid foam sandwich beam, TFS) was proposed. Tooth plate was connected with foam core through tooth nails, which is different from FML facesheets, in which the metal plate and the glass fiber-reinforced composite were bonded together. Three-point bending test and DCB (double cantilever beam) test were carried out to obtain the load-displacement curves, failure modes, bending properties, and interlaminar behavior of the sandwich structures. Meanwhile, an analysis model was proposed to predict the peak load of the TFS.

\section{Experimental Program}

2.1. Specimens. Specimens were fabricated using a vacuumassisted resin infusion process at Composite Structure Lab of Nanjing Tech University. The materials used in the specimens were polyurethane foam with various density $\left(35 \mathrm{~kg} / \mathrm{m}^{3}\right.$, $80 \mathrm{~kg} / \mathrm{m}^{3}$, and $150 \mathrm{~kg} / \mathrm{m}^{3}$ ), Q235 steel, galvanized metal tooth nail made by punching machine, E-type glass fiber fabric without alkali with density of $800 \mathrm{~g} / \mathrm{m}^{2}$, and the HS-2100-type two formic acid unsaturated polyester resin. The thickness of tooth plate is $0.7 \mathrm{~mm}$, with tooth length of $8 \mathrm{~mm}$, width of $3 \mathrm{~mm}$, each pair of teeth along the longitudinal spacing of $25 \mathrm{~mm}$, horizontal spacing of $12 \mathrm{~mm}$, and cross equidistant arrangement. At first, the surface of metal plate was modified with organic solvent (such as acetone) to remove the surface grease. The steel tooth plates were pressed into polyurethane foam, and then the upper and lower surfaces of tooth plate were covered with two layers of glass fiber fabric and the fiber orientation angel is $0 / 90^{\circ}$ to the panel horizontal axis. Finally, the vacuum-assisted resin infusion process was used to fabricate the specimens, in which all the raw materials were immersed by the resin. The real component is shown in Figure 1. The similar sandwich beams with fiber facesheet thickness of $1.5 \mathrm{~mm}$ and $2.1 \mathrm{~mm}$ were fabricated to compare with the TFS specimens.

2.2. Material Properties. Tension tests of steel facesheets and GFRP facesheets were conducted according to ASTM D 3039 [17] to characterize the mechanical properties of the materials. The strength and stiffness of the steel sheets and GFRP sheets obtained from these experiments were detailed in Table 1. The tensile strength and elastic modulus of tooth plate were equivalent strength and elastic modulus, 


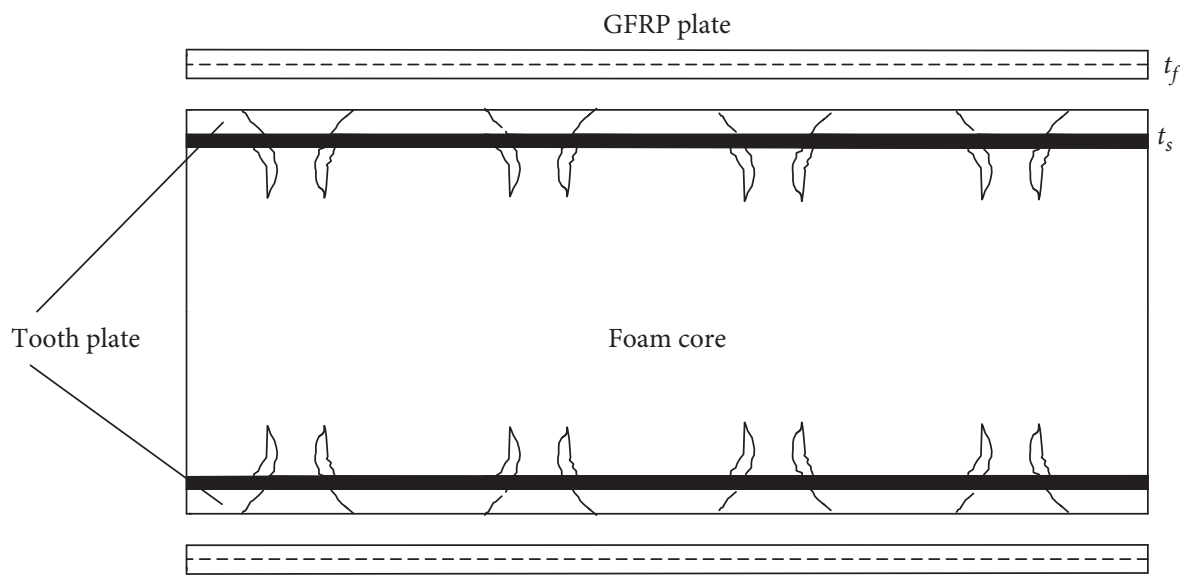

(a)

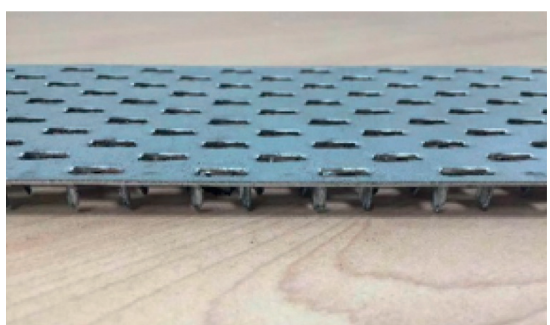

(b)

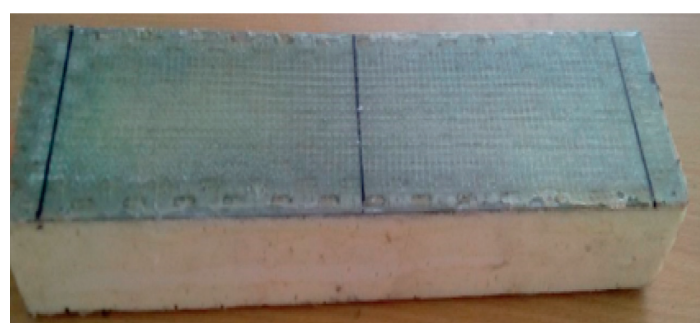

(c)

FIgURE 1: (a) Schematic illustration of TFS specimen; (b) photo of tooth plate; (c) photo of TFS specimen.

TABLE 1: Mechanical properties of GFRP and tooth plate.

\begin{tabular}{lcc}
\hline Type & Tensile strength $(\mathrm{MPa})$ & Elastic modulus $(\mathrm{GPa})$ \\
\hline 2 layers of GFRP & 150.73 & 8.53 \\
3 layers of GFRP & 178.90 & 9.32 \\
Tooth plate & 111.02 (equivalent) & 50.02 (equivalent) \\
\hline
\end{tabular}

for there were regularly arranged holes on the tooth plate. In order to obtain the compressive strength and Young's modulus of the foam specimens, polyurethane (PU) foam specimens with dimension of $50 \times 50 \times 50 \mathrm{~mm}^{3}$ were prepared and tested according to ASTM D 1621 [18]. Foam samples were tested under displacement control mode with loading rate of $0.5 \mathrm{~mm} / \mathrm{min}$. The mechanical behavior of PU foam was given in Table 2. To achieve more accurate numerical results, three samples of each dimension had been tested and the mean values of the data had been calculated as the final results.

2.3. Three-Point Bending Tests. In order to evaluate the flexural behavior of TFS beams, three-point bending tests were conducted according to ASTM C 393-62 [19]. For each span, there were three specimens. In Figure 2, all specimens had the same width $(b=75 \mathrm{~mm})$ and core height $(h=40 \mathrm{~mm})$. Specimens NS3D1, NS3D2, and NS3D3 were the ordinary sandwich beams with GFRP facesheets. The other specimens were strengthened by tooth plate with various density $(\rho)$ and span $(s)$. The details of specimens were shown in Table 3. T in specimen name is the symbol of
TABLE 2: Mechanical properties of foam core.

\begin{tabular}{lccc}
\hline Density $\left(\mathrm{kg} / \mathrm{m}^{3}\right)$ & 35 & 80 & 150 \\
\hline Compressive strength $(\mathrm{MPa})$ & 0.10 & 0.35 & 0.92 \\
Shear strength $(\mathrm{MPa})$ & 0.10 & 0.28 & 0.43 \\
Compressive modulus $(\mathrm{GPa})$ & 6.76 & 18.56 & 48.51 \\
Shear modulus $(\mathrm{GPa})$ & 2.84 & 8.06 & 18.56 \\
\hline
\end{tabular}

the sandwich beams with tooth plate facesheets. Beam spans of $300 \mathrm{~mm}, 400 \mathrm{~mm}$, and $500 \mathrm{~mm}$, respectively, were presented as S3, S4, and S5 and foam density of $35 \mathrm{~kg} / \mathrm{m}^{3}$, $80 \mathrm{~kg} / \mathrm{m}^{3}$, and $150 \mathrm{~kg} / \mathrm{m}^{3}$ was presented as D1, D2, and D3. All the specimens were loaded under displacement control mode with loading rate of $2.0 \mathrm{~mm} / \mathrm{min}$ and load-displacement data were recorded by a universal test machine with the capacity of $200 \mathrm{kN}$.

2.4. Double Cantilever Beam Tests. In order to study the interfacial fracture behavior of TFS beams, double cantilever beam test was performed in accordance with ASTM 5528-01 [20]. In this study, the specimens with different core density $\left(35 \mathrm{~kg} / \mathrm{m}^{3}, 80 \mathrm{~kg} / \mathrm{m}^{3}\right.$, and $\left.150 \mathrm{~kg} / \mathrm{m}^{3}\right)$ were fabricated using a vacuum-assisted resin infusion process. In Figure 3, an initial interface crack had been made between the upper facesheet and the foam core. The lengths of specimen and initial crack were $254 \mathrm{~mm}$ and $50 \mathrm{~mm}$, and the thicknesses of foam core and facesheet and were $40 \mathrm{~mm}$ and $2.2 \mathrm{~mm}$. Metallic hinges were glued on both sides of the facesheets. The loading cell and a steel block bonded on the upper 


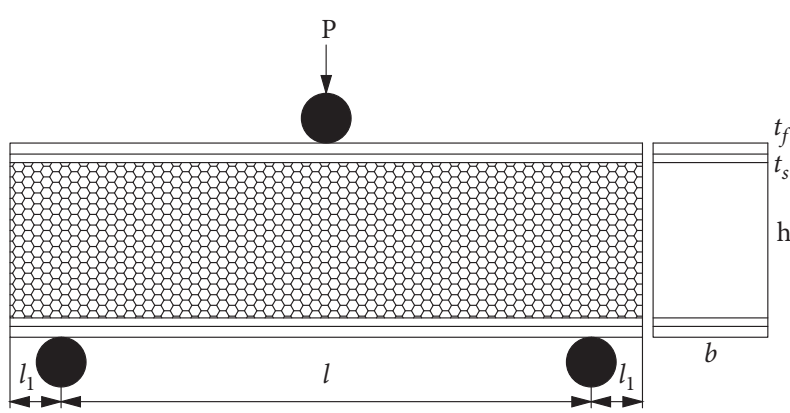

(a)

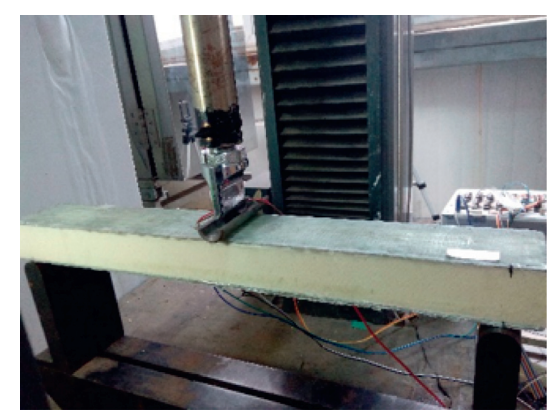

(b)

Figure 2: (a) Three-point bending test configuration according to ASTM C 393-62; (b) test specimen under loading.

TABle 3: Specimen parameters of ordinary sandwich beams and hybrid sandwich beams.

\begin{tabular}{|c|c|c|c|c|c|c|}
\hline Specimen & $H(\mathrm{~mm})$ & $L(\mathrm{~mm})$ & $l(\mathrm{~mm})$ & $t_{f}$ & $t_{s}$ & $\rho\left(\mathrm{kg} / \mathrm{m}^{3}\right)$ \\
\hline NS3D1 & 44.2 & 340 & 300 & 2.1 & - & 35 \\
\hline NS3D2 & 44.2 & 340 & 300 & 2.1 & - & 80 \\
\hline NS3D3 & 44.2 & 340 & 300 & 2.1 & - & 150 \\
\hline TS3D1 & 44.4 & 340 & 300 & 1.5 & 0.8 & 35 \\
\hline TS3D2 & 44.4 & 340 & 300 & 1.5 & 0.8 & 80 \\
\hline TS3D3 & 44.4 & 340 & 300 & 1.5 & 0.8 & 150 \\
\hline TS4D1 & 44.4 & 440 & 400 & 1.5 & 0.8 & 35 \\
\hline TS4D2 & 44.4 & 440 & 400 & 1.5 & 0.8 & 80 \\
\hline TS4D3 & 44.4 & 440 & 400 & 1.5 & 0.8 & 150 \\
\hline TS5D1 & 44.4 & 540 & 500 & 1.5 & 0.8 & 35 \\
\hline TS5D2 & 44.4 & 540 & 500 & 1.5 & 0.8 & 80 \\
\hline TS5D3 & 44.4 & 540 & 500 & 1.5 & 0.8 & 150 \\
\hline
\end{tabular}

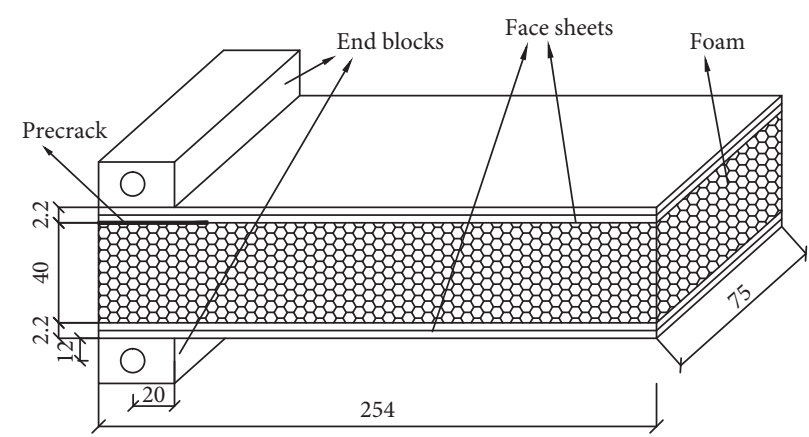

(a)

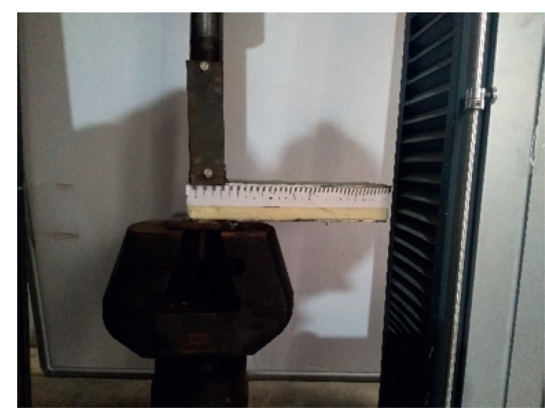

(b)

Figure 3: (a) Test setup of DCB tests (unit: mm); (b) DCB specimen.

facesheet were connected by a stainless bar. In order to monitor the length of the crack propagation, the specimen edges were coated with a thin layer of water-soluble correction fluid from the side of the initial crack. The specimens were tested under displacement control mode with loading rate of $2.0 \mathrm{~mm} / \mathrm{min}$. During the tests, the load-displacement data were recorded by the computer whereas the crack lengths were recorded by a high-resolution digital camera. In addition, it should be mentioned in this context that there were not any separation between the FRP and tooth plate in all the tests.

\section{Results and Discussions}

3.1. Flexural Characteristic of Sandwich Structures. The test results of all specimens under three-point bending loading conditions, including the peak strength $\left(P_{u}\right)$ and absorbed energy $\left(E_{a}\right)$, were summarized in Table 4 . The load-displacement data recorded during the tests were plotted in Figure 4. Figure 4(a) showed the effects of tooth plate on $P_{u}$ of sandwich beams. Comparing with NS3D1 $\left(P_{u}=234 \mathrm{~N}\right)$, NS3D2 $\left(P_{u}=490 \mathrm{~N}\right)$, and NS3D3 $\left(P_{u}=916 \mathrm{~N}\right)$, the peak load of specimens TS3D1, TS3D2, and TS3D3 increased by $168 \%$, 
TABLE 4: Absorbed energy and peak load of specimens.

\begin{tabular}{lcc}
\hline Specimen & $E_{a}(\mathrm{~J})$ & $P_{u}(\mathrm{~N})$ \\
\hline NS3D1 & 1.15 & 234 \\
NS3D2 & 1.29 & 490 \\
NS3D3 & 1.14 & 916 \\
TS3D1 & 19.72 & 627 \\
TS3D2 & 23.28 & 1524 \\
TS3D3 & 32.42 & 3280 \\
TS4D1 & 13.80 & 605 \\
TS4D2 & 21.20 & 1421 \\
TS4D3 & 25.04 & 2784 \\
TS5D1 & 12.25 & 576 \\
TS5D2 & 17.86 & 1362 \\
TS5D3 & 21.95 & 2218 \\
\hline
\end{tabular}
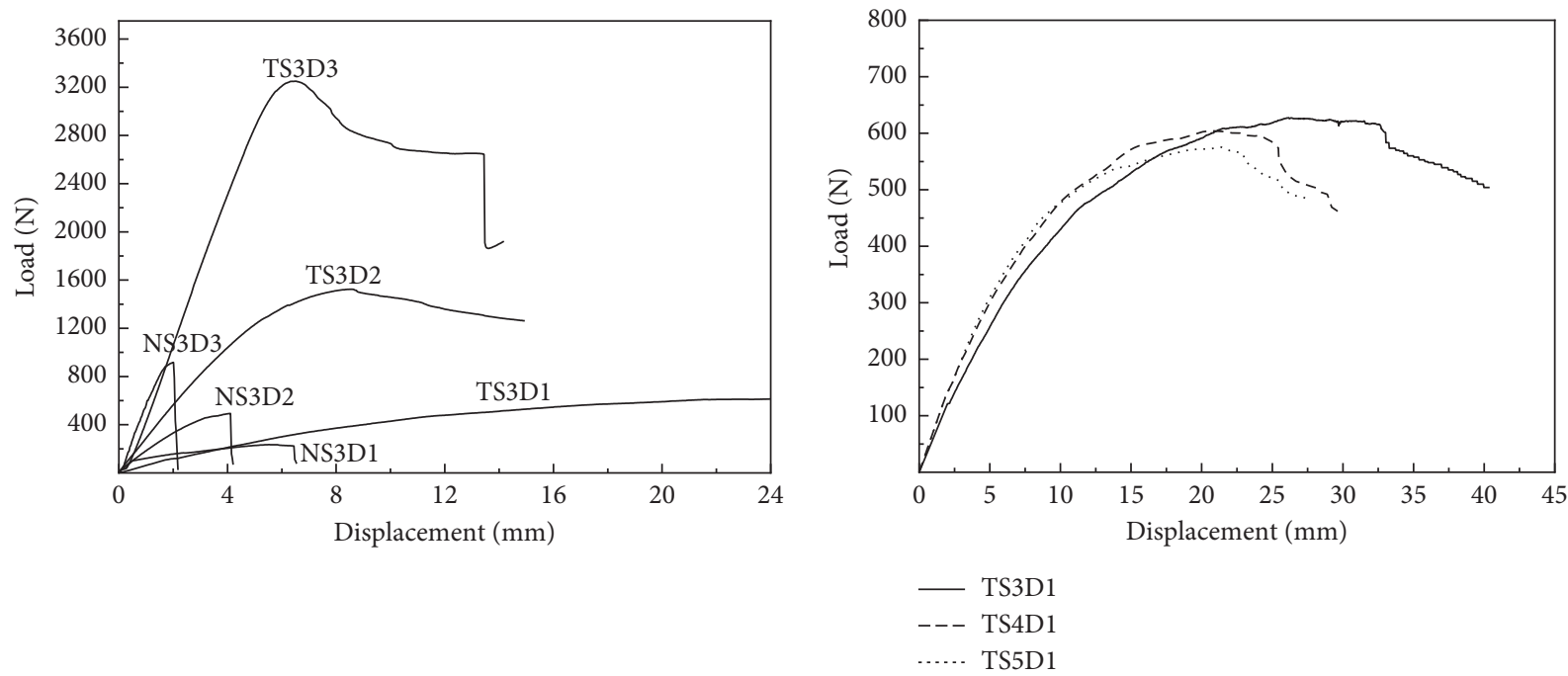

(a)

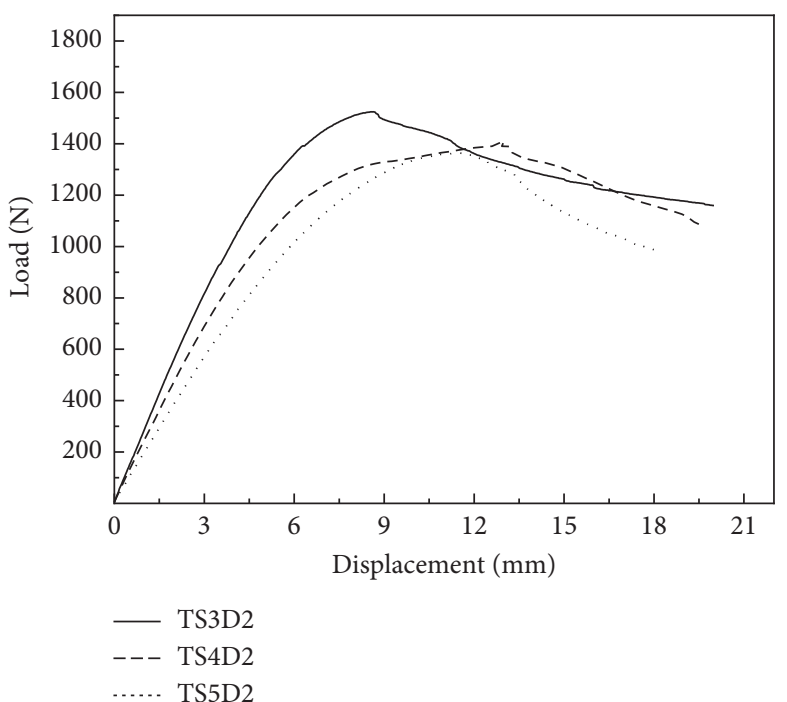

(c) (b)

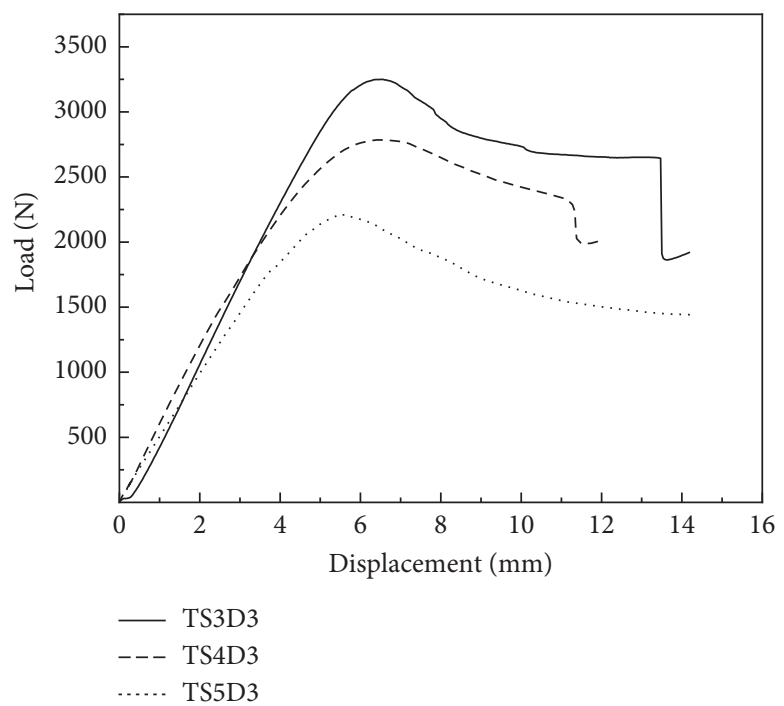

(d)

Figure 4: The load-displacement curves of specimens: (a) the normal sandwich beams and TFS beams with 300 span length, (b) the TFS beams with different span length and $35 \mathrm{~kg} / \mathrm{m}^{3}$ foam core, (c) the TFS beams with different span length and $80 \mathrm{~kg} / \mathrm{m}^{3}$ foam core, and (d) the TFS beams with different span length and $150 \mathrm{~kg} / \mathrm{m}^{3}$ foam core. 
$211 \%$, and $258 \%$, respectively. It is due to the fact that the tooth plate could significantly increase the stiffness of facesheets. Hence, the use of tooth plate can increase the peak strength of sandwich beams significantly. Figure 4(a) also showed the effects of foam density on $P_{u}$ of TFS beams. For the specimens with $300 \mathrm{~mm}$ span, $P_{u}$ of TS3D2 and TS3D3 were $1524 \mathrm{~N}$ and $3280 \mathrm{~N}$, which were $143 \%$ and $423 \%$ larger than $P_{u}$ of specimen TS3D1, respectively. That is mainly due to the fact that the foam with higher density has a higher strength. Higher density of foam can provide a good resistance to the applied load. Additionally, since the metal tooth had been embedded into the core foam, the debonding failure could scarcely be witnessed, in which the core foam with higher density enhanced the laminar property between the tooth surface and the core foam.

The effects of foam density on the energy absorption of TFS beams were illustrated in Figure 5. For the specimens with $300 \mathrm{~mm}$ span, $E_{a}$ of specimens TS3D2 and TS3D3 were $23.28 \mathrm{~J}$ and $32.40 \mathrm{~J}$, which were $18.1 \%$ and $64.3 \%$ larger than those of specimen TS3D1. For the specimens with $400 \mathrm{~mm}$ span, $E_{a}$ of specimens TS4D2 and TS4D3 were $21.2 \mathrm{~J}$ and $25.04 \mathrm{~J}$, which were $53.6 \%$ and $81.7 \%$ larger than those of specimen TS4D1. For the specimens with $500 \mathrm{~mm}$ span, $E_{a}$ of specimens TS5D2 and TS5D3 were $17.86 \mathrm{~J}$ and $21.95 \mathrm{~J}$, which were $45.8 \%$ and $79.1 \%$ larger than those of Specimen TS3D1. Therefore, the energy absorption capacity of TFS beams could be improved by increasing the foam density.

According to the load-displacement curves, all specimens exhibited an initial linear-elastic response with a subsequent nonlinear part near to the peak load. The foam density increase resulted in the increase of both equivalent flexural stiffness and the slope of the linear-elastic region. The force level after peak load showed some differences between TFS and sandwich beams with fiber composite faces. For TFS specimens, the load-displacement curves exhibited a smooth force drop after the maximum force value. However, an abrupt load drop was observed in the normal sandwich beams after the peak value, which was associated with foam failed by bulking of cell walls and edges. Hence, it can be concluded that TFS beams have a good integrity after plateau region and good resistance against transverse loads. Two main failure modes were observed during the bending tests: core shear and the facesheet indentation. For TFS specimens with foam density of $35 \mathrm{~kg} / \mathrm{m}^{3}$ and $80 \mathrm{~kg} / \mathrm{m}^{3}$, the main failure mode was facesheet indentation beneath the loading roller, which is shown in Figure 6(a). For TFS specimens with span of $400 \mathrm{~mm}$ and $500 \mathrm{~mm}$ and foam density of $150 \mathrm{~kg} / \mathrm{m}^{3}$, the failure mode was core shear. Shearing of the foam core occurred between upper loading indenter and lower support. The direction of shear crack was about $45^{\circ}$ angel to the horizontal, which is shown in Figure 6(b). For TFS specimens with $300 \mathrm{~mm}$ span length, the failure mode was facesheet indentation.

3.2. Failure Mechanical of Double Cantilever Tests. As shown in Figure 7, the failure in the DCB specimen was mainly through the interface. The typical load-displacement curves

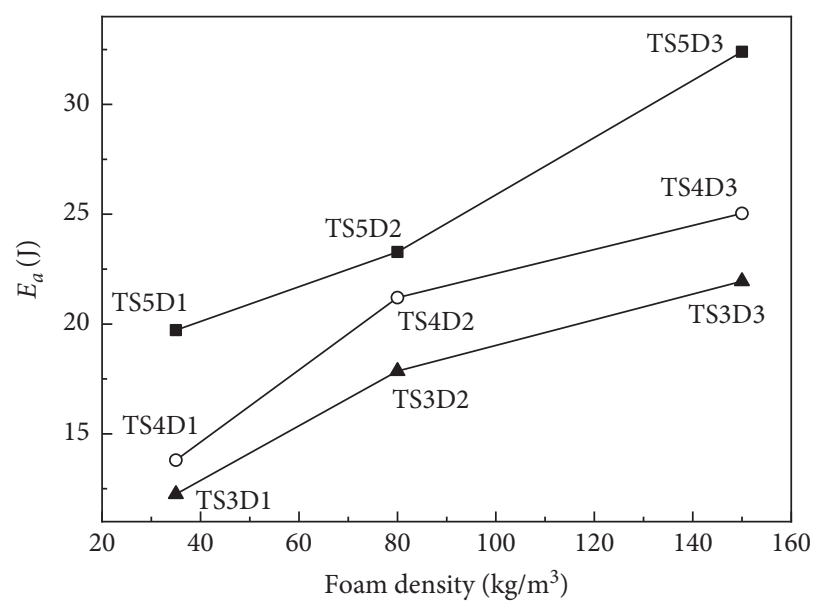

Figure 5: The effects of foam density on energy absorption of TFS beams.

obtained from the tests were shown in Figure 8. It could be found that the initial loading curves exhibited a linear-elastic response and the crack propagation was stable. After the peak load, the curves showed a saw-tooth and the growth of the crack propagation turned unstable.

The energy release rate was calculated by the experimental compliance calibration method. The compliance $(C)$ is the ratio of load and displacement during the test, which can be determined using the following equation:

$$
C=\frac{\delta}{P},
$$

where $P$ is the load and $\delta$ is the load point displacement.

The relationship of specimen compliance versus crack length could be expressed as [21]

$$
C=C_{0} a^{m},
$$

where $a$ is the crack length and $C_{0}$ and $m$ are experiment determined constants measured from a linear fit to double logarithmic plot of $C$ versus $a$. The value of $m$ is the slope of compliance data.

The strain energy release rate of mode I interfacial fracture can be calculated by the Irwin-Kies equation [22]:

$$
G_{I}=\frac{P^{2}}{2 b} \frac{d C}{d a}
$$

leading to

$$
G_{I}=\frac{P^{2}}{2 b}\left(m C_{0} a^{m-1}\right)
$$

in which $b$ is the width of the specimen.

A typical double logarithmic plot of TFS specimen compliance versus the crack length is shown in Figure 9. From the figure, the slopes were found to be $2.174,2.012$, and 2.869 with foam density of $35 \mathrm{~kg} / \mathrm{m}^{3}, 80 \mathrm{~kg} / \mathrm{m}^{3}$, and $150 \mathrm{~kg} /$ $\mathrm{m}^{3}$. To bring constant $m$ into equation (4) can obtain the experimental strain release rate of this system. Figure 10 showed a typical plot of strain energy rate versus crack length for DCB specimens loaded at $1 \mathrm{~mm} / \mathrm{min}$. It was found that the peak value of strain energy release rate increased 


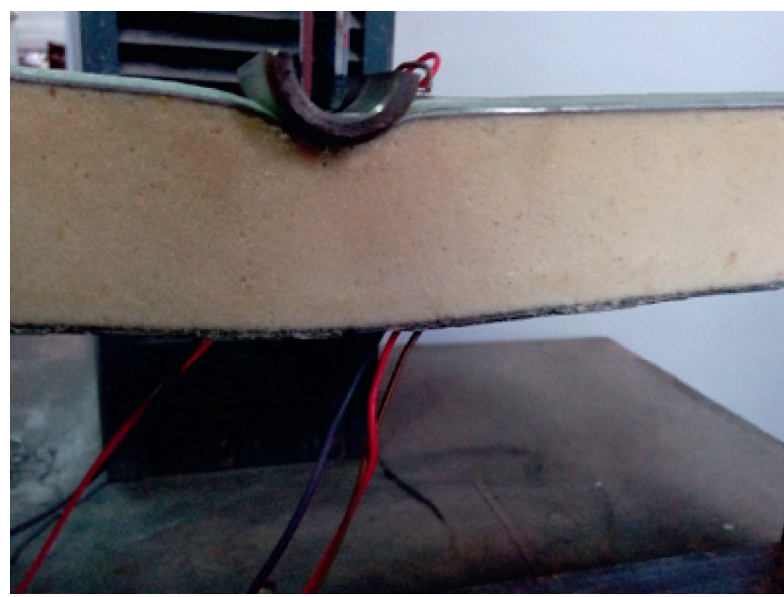

(a)

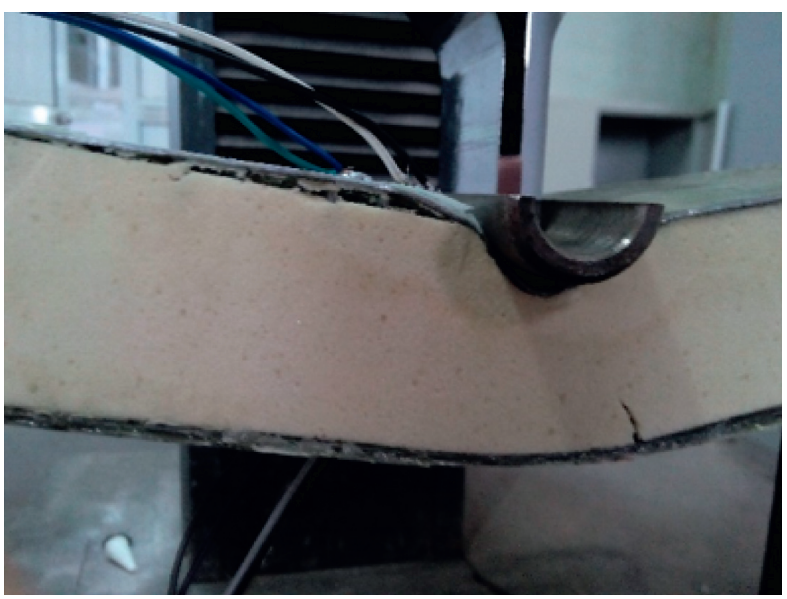

(b)

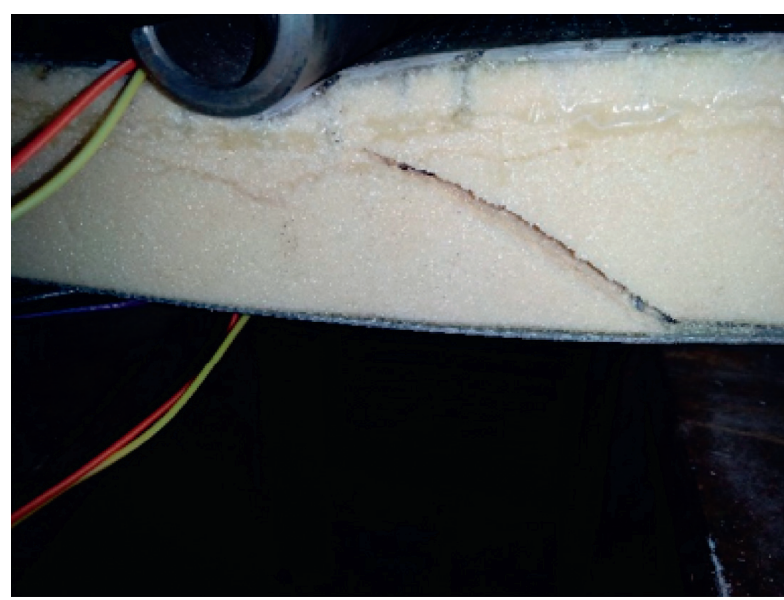

(c)

FIGURE 6: The failure modes of TFS beams: (a) core indentation failure of hybrid sandwich beams with foam core density of $35 \mathrm{~kg} / \mathrm{m}^{3}$, (b) core indentation failure of hybrid sandwich beams with foam core density of $80 \mathrm{~kg} / \mathrm{m}^{3}$, and (c) core shear failure of hybrid sandwich beams with foam core density of $150 \mathrm{~kg} / \mathrm{m}^{3}$ under the span of $300 \mathrm{~mm}$ and $400 \mathrm{~mm}$.

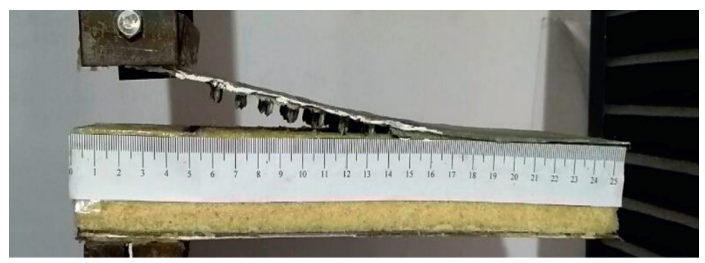

(a)

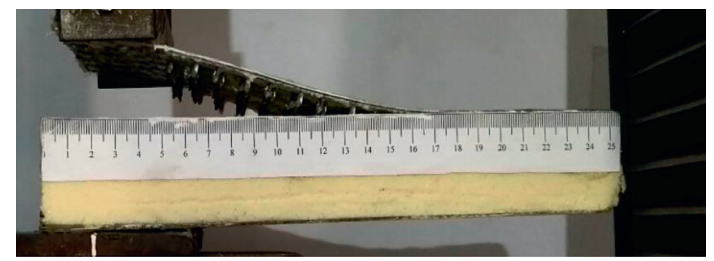

(b)

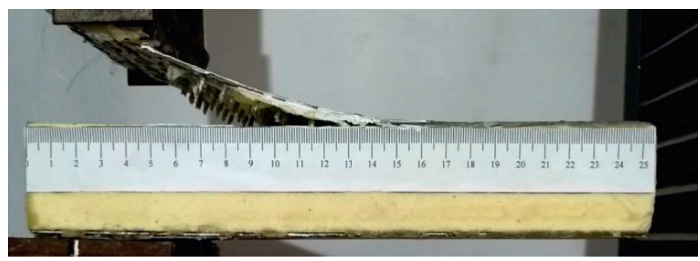

(c)

FIGURE 7: Failure mode of DCB specimen: (a) DCB specimen of $35 \mathrm{~kg} / \mathrm{m}^{3}$ foam core, (b) DCB specimen of $80 \mathrm{~kg} / \mathrm{m}^{3}$ foam core, and (c) DCB specimen of $150 \mathrm{~kg} / \mathrm{m}^{3}$ foam core. 


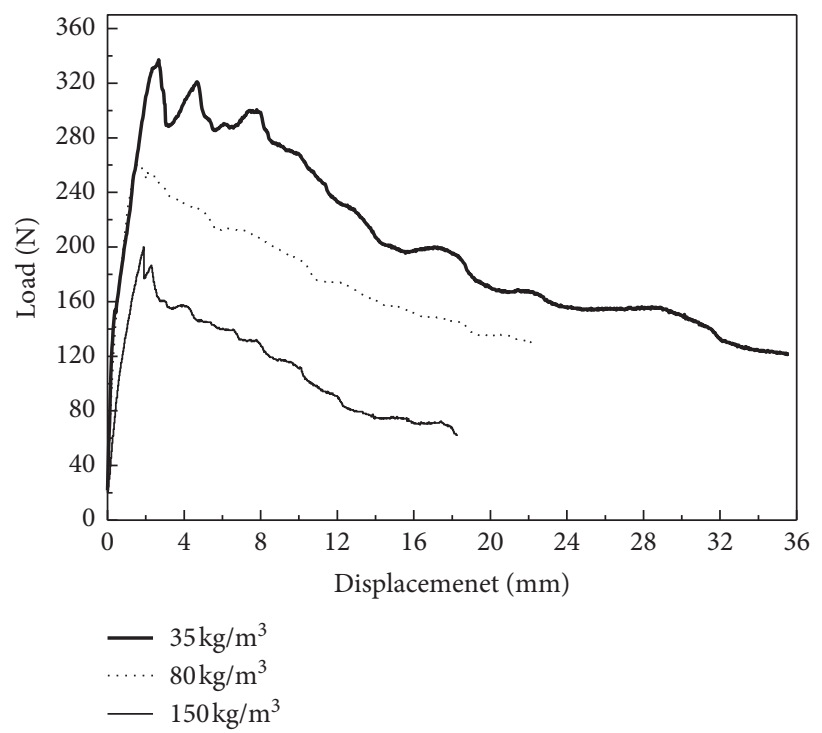

FIGURE 8: Load-displacement curves of DCB specimens.

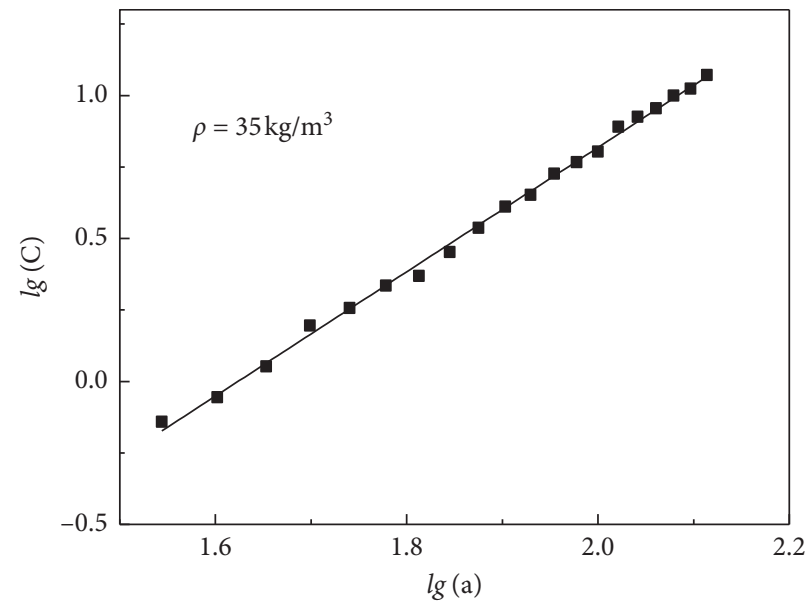

- Test results

Fitting curve $(y=2.174 x-3.529)$

(a)

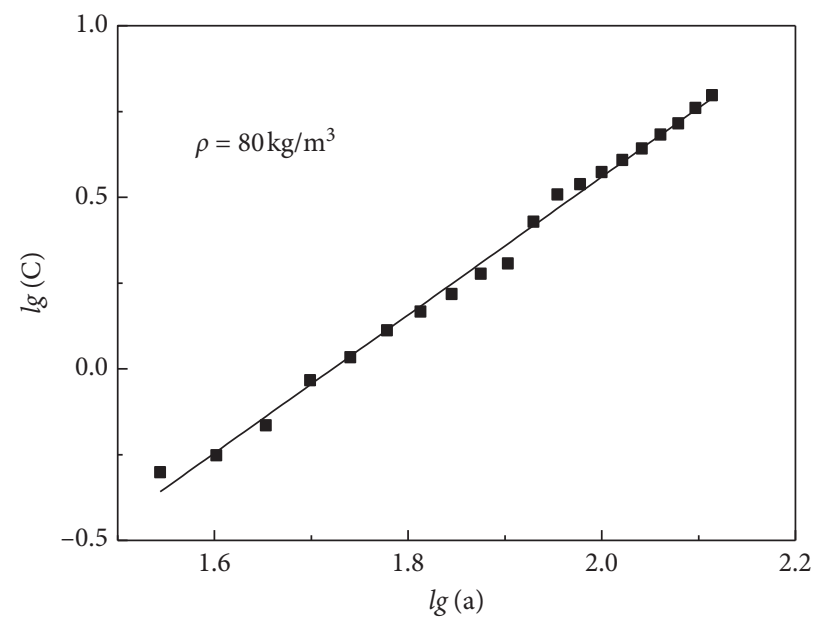

- Test results

Fitting curve $(y=2.012 x-3.465)$

(b)

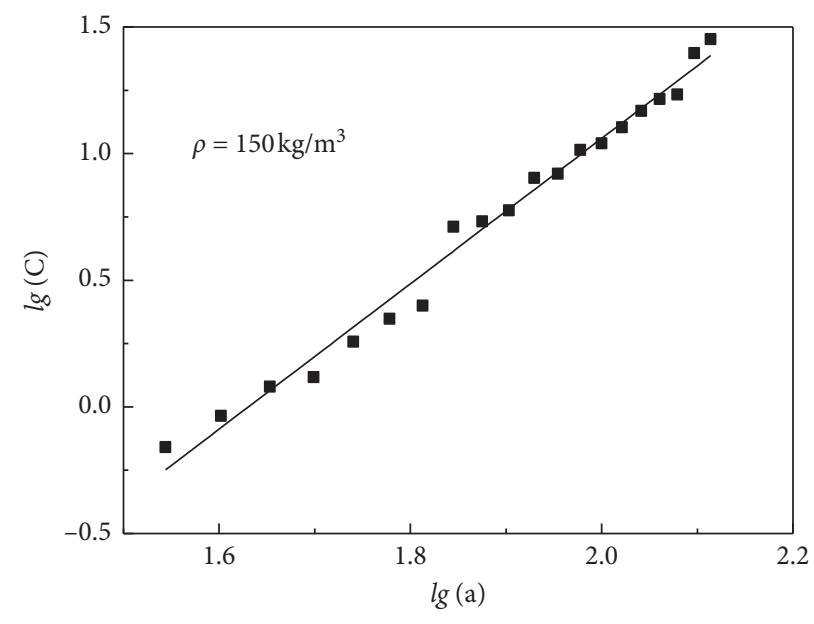

- Test results

Fitting curve $(y=2.869 x-4.678)$

(c)

FIgURE 9: The values of $m$ determined under different foam core density. 


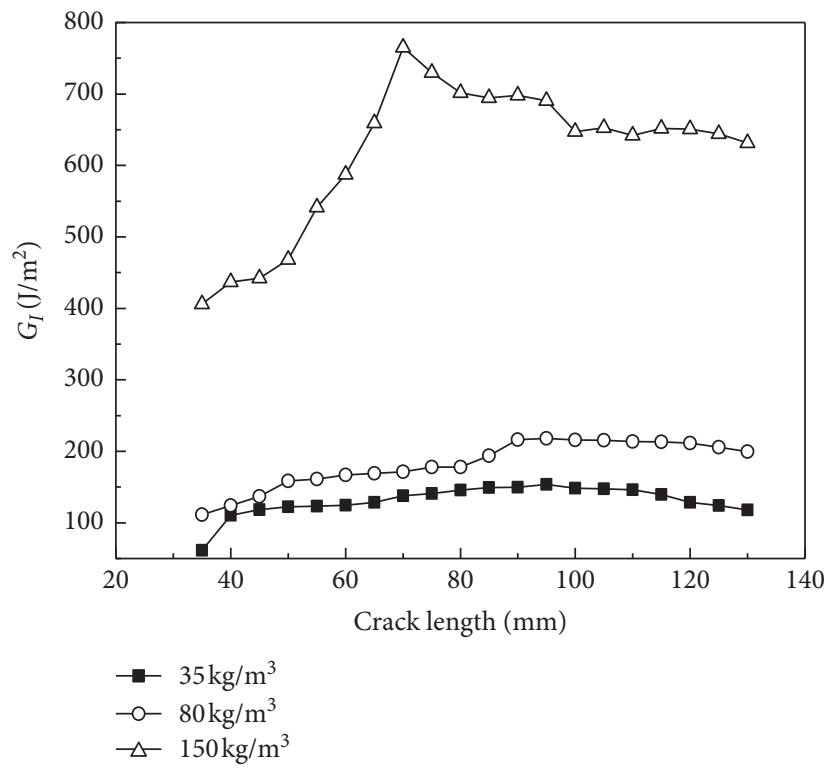

FIGURE 10: Strain energy release rate of specimens under different foam core density.

with the increase of foam density. Compared with the specimens of foam density $35 \mathrm{kgm}^{3}$, the peak value of strain energy release rate increased by $100 \%$ and $600 \%$, respectively. It was concluded that the density of foam core had a great effect on the value of strain energy release rate in Figure 10.

\section{Analysis Model}

An analytical model was used to predict the peak loading of TFS beam under three-point bending test, including the failure modes of foam core shear and facesheet indentation (seen in Figure 11).

4.1. Core Shear. The shear failure occurs when the transverse shear stress exceeds the core shear strength. The collapse mechanics could be defined in equation (5). It had been assumed that the facesheets on the right side of the sandwich panel rotates through an angle $\theta$ whereas the left side rotates through $-\theta$. Thus, the foam core shears by an angle $2 \theta$. It had been assumed that the bottom facesheet is subjected to tensile fracture when the foam core shear failure.

The external work done by applied load can be calculated by the following equation:

$$
W_{e}=\frac{P l \theta}{2} .
$$

Internal work absorbed by the foam core and facesheet can be calculated by the following equation [23]:

$$
W_{i}=4 M_{f}^{\prime} \theta+b t_{c} \tau_{c}\left(2 l_{1}+l\right) \theta,
$$

in which $\tau_{c}$ is the core shear strength, $b$ is the width of TFS beams, and $M_{f}^{\prime}$ is the initial bending moment of brittle fracture of hybrid facesheet, which can be calculated by the following equation:

$$
M_{f}^{\prime}=\frac{b t_{f}^{2}}{6} \sigma_{f y}+\frac{b t_{s}^{2}}{6} \sigma_{s y},
$$

in which $t_{f}$ and $t_{s}$ are the thickness of facesheet and tooth plate, respectively, and $\sigma_{f y}$ and $\sigma_{s y}$ are the tensile strength of GFRP skin and tooth plate. Equating the external work done by applied force $P$ to the internal work, the peak load due to core shear failure of composite sandwich beam could be obtained by the following equation:

$$
P_{c r}=2 b t_{c} \tau_{c} \frac{2 l_{1}+l}{l}+\frac{4 b\left(t_{f}^{2} \sigma_{f y}+t_{s}^{2} \sigma_{s y}\right)}{3 l} .
$$

4.2. Indentation. In three-point bending, the bending moment induced by the applied transverse load $P$ is $M=P l / 4$, the compressive axial force of upper facesheet is $F=M$ / $\left(c+t_{f}\right)$ and the lower facesheet experiences a tensile force of equal magnitude. The indentation failure occurs if the foam core is compressed by mid-roller with an indentation zone of $2 \lambda$ in a rigid-ideally plastic manner. The transverse load from sandwich face to foam core is $q=\sigma_{c} b$, where $\sigma_{c}$ is the crushing strength of a rigid-ideally plastic core and $b$ is the width of the TFS beam, as shown in Figure 11. The indentation failure had been analyzed by Steeves and Fleck [7] based on a plastically deforming foundation model. The indentation failure load could be calculated by the following equation:

$$
P=b\left(t_{s}+t_{f}\right)\left(\frac{\pi^{2} \sigma_{c}^{2} E_{f}^{\prime}\left(t_{s}+t_{f}+c\right)}{3 l}\right)^{1 / 3},
$$

where $c$ is the thickness of foam core and $E_{f}^{\prime}$ is the equivalent elastic modulus of hybrid facesheet, which can be calculated by the following equation: 


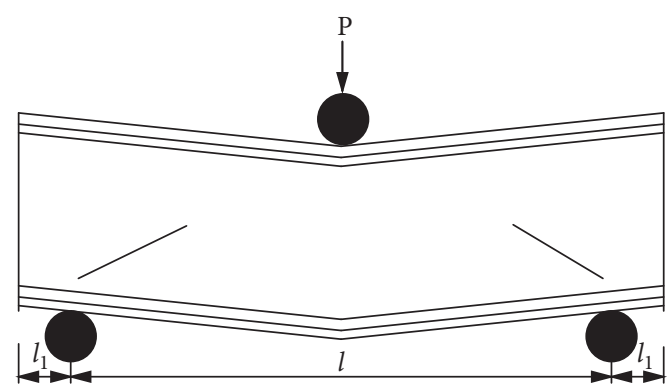

(a)

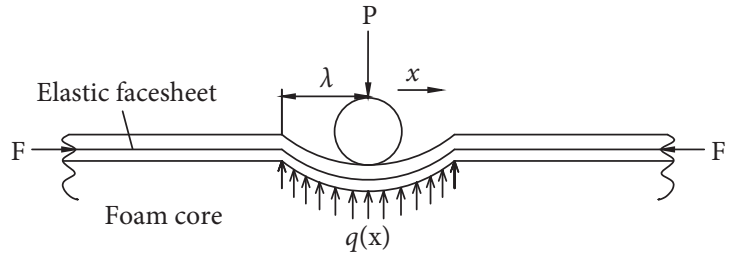

(b)

FIgURE 11: Failure types of TFS sandwich structures: (a) core shear failure and (b) indentation.

TABLE 5: Comparison of experimental and analytical results.

\begin{tabular}{|c|c|c|c|c|}
\hline \multirow[b]{2}{*}{ Specimen } & \multicolumn{2}{|c|}{ Ultimate load $(\mathrm{kN})$} & \multirow[b]{2}{*}{ Difference } & \multirow[b]{2}{*}{ Failure mode } \\
\hline & $\begin{array}{c}\text { Test } \\
\text { result }\end{array}$ & $\begin{array}{l}\text { Analytical } \\
\text { result }\end{array}$ & & \\
\hline TS3D1 & 0.627 & 0.767 & $22.3 \%$ & Indentation \\
\hline TS4D1 & 0.605 & 0.697 & $15.2 \%$ & Indentation \\
\hline TS5D1 & 0.576 & 0.647 & $12.3 \%$ & Indentation \\
\hline TS3D2 & 1.524 & 1.769 & $16.1 \%$ & Indentation \\
\hline TS4D2 & 1.412 & 1.607 & $13.8 \%$ & Indentation \\
\hline TS5D2 & 1.362 & 1.492 & $9.5 \%$ & Indentation \\
\hline TS3D3 & 3.280 & 3.055 & $-6.9 \%$ & Core shear \\
\hline TS4D3 & 2.784 & 2.936 & 5.5 & Core shear \\
\hline TS5D3 & 2.218 & 2.738 & $23.4 \%$ & Indentation \\
\hline
\end{tabular}

$$
E_{f}^{\prime}=\frac{E_{f} t_{f}+E_{s} t_{s}}{t_{f}+t_{s}},
$$

where $E_{f}$ and $E_{s}$ are the elastic modulus of GFRP and tooth plate, respectively.

The predicted peak load of TFS beams under three-point bending load condition is presented in Table 5. By comparing the analytical and experimental results, it was found that the largest variation between predicted and experimental results in peak load was 23.4\%. Mostly, the peak load of TFS can be well predicted by the analytical model. For the failure mode of indentation, the differences were greater than the mode of core shear, probably due to the special structure of the facesheets. Equation (9) could not consider the holes in the tooth plates, which were surrounded by the resins and fibers in the facesheet.

\section{Conclusion}

In this study, three-point bending tests and double cantilever tests had been conducted on a new family of sandwich beams with fiber-metal hybrid facesheets. Both foam core density and span length parameters were selected to investigate the flexural behavior of sandwich structures. From the tests, the following conclusions can be obtained through the above research:

(1) For common composite sandwich structure, there were many kinds of failure modes, like indentation, core shear, facesheet debonding, and kinking, under bending load. Because of the insertion of the tooth plate, just indentation mode and core shear mode happened, while some initial interfacial failures were avoided, which indicates that the tooth in the steel plate could effectively enhance the interlaminar behavior.

(2) With the increasing of foam density, the foam shear strength and compressive strength improved. Tooth plate in the specimens had minor influence on the shear behavior, while it could improve the local indentation of the facesheet for its higher stiffness compared to FRP. The core material could support the facesheets more effectively, and it suppressed the local compression at the loading point, which was the major factor that ultimate bending capacity increased.

(3) The interlaminar behavior had been further researched in DCB test. In the test, there was no damage on the tooth plate, while foam cracked into the internal part of the core, unlike the nearby interfacial damage in common FRP sandwich beam. The foam was obviously weaker than the steel tooth plate, so the damage happened in the foam. There was still potential improvement by increasing the core material properties.

\section{Data Availability}

The data used to support the findings of this study are available from the corresponding author upon request.

\section{Conflicts of Interest}

The authors declare that they have no conflicts of interest.

\section{Acknowledgments}

This research was supported by the Key Program of National Natural Science Foundation of China (Grant no. 51238003) and Key University Science Research Project of Jiangsu Province (Grant no. 15KJA560001).

\section{References}

[1] L. C. Hollaway, "A review of the present and future utilisation of FRP composites in the civil infrastructure with reference to 
their important in-service properties," Construction and Building Materials, vol. 24, no. 12, pp. 2419-2445, 2010.

[2] L. B. Vogelesang and A. Vlot, "Development of fibre metal laminates for advanced aerospace structures," Journal of Materials Processing Technology, vol. 103, no. 1, pp. 1-5, 2000.

[3] H. G. Vlot and J. E. Perez Ipiña, "Short-beam shear fatigue behavior of fiber metal laminate (Glare)," International Journal of Fatigue, vol. 95, pp. 236-242, 2017.

[4] R. Alderliesten and J. Homan, "Fatigue and damage tolerance issues of Glare in aircraft structures," International Journal of Fatigue, vol. 28, no. 10, pp. 1116-1123, 2006.

[5] E. K. Baumert, W. S. Johnson, R. J. Cano, B. J. Jensen, and E. S. Weiser, "Fatigue damage development in new fibre metal laminates made by the VARTM process," Fatigue \& Fracture of Engineering Materials \& Structures, vol. 34, no. 4, pp. 240-249, 2011.

[6] M. H. Kashani, M. Sadighi, M. Mohammadkhah, and H. S. Alavijeh, "Investigation of scaling effects on fiber metal laminates under tensile and flexural loading," Proceedings of the Institution of Mechanical Engineers, Part L: Journal of Materials: Design and Applications, vol. 229, no. 3, pp. 189201, 2015.

[7] C. A. Steeves and N. A. Fleck, "Collapse mechanisms of sandwich beams with composite faces and a foam core, loaded in three-point bending-part I: analytical models and minimum weight design," International Journal of Mechanical Sciences, vol. 46, no. 4, pp. 561-583, 2004.

[8] K. Kabir, T. Vodenitcharova, and M. Hoffman, "Response of aluminium foam-cored sandwich panels to bending load," Composites Part B: Engineering, vol. 64, pp. 24-32, 2014.

[9] S. Dariushi and M. Sadighi, "A study on flexural properties of sandwich structures with fiber/metal laminate face sheets," Applied Composite Materials, vol. 20, no. 5, pp. 839-855, 2013.

[10] G. Reyes, "Mechanical behavior of thermoplastic FML-reinforced sandwich panels using an aluminum foam core: experiments and modeling," Journal of Sandwich Structures \& Materials, vol. 12, no. 1, pp. 81-96, 2010.

[11] I. Ortiz de Mendibil, M. Sarrionandia, M. Mateos, J. Aurrekoetxea, and L. Aretxabaleta, "Impact behaviour of glass fibre-reinforced epoxy/aluminium fibre metal laminate manufactured by Vacuum Assisted Resin transfer moulding," Composite Structures, vol. 140, pp. 118-124, 2016.

[12] G. Reyes Villanueva and W. J. Cantwell, "The high velocity impact response of composite and FML-reinforced sandwich structures," Composites Science and Technology, vol. 64, no. 1, pp. 35-54, 2004.

[13] J. G. Carrillo and W. J. Cantwell, "Mechanical properties of a novel fiber-metal laminate based on a polypropylene composite," Mechanics of Materials, vol. 41, no. 7, pp. 828-838, 2009.

[14] D. Srinivasagupta, B. Joseph, P. Majumdar, and H. Mahfuz, "Effect of processing conditions and material properties on the debond fracture toughness of foam-core sandwich composites: process model development," Composites Part A: Applied Science and Manufacturing, vol. 34, no. 11, pp. 1085-1095, 2003.

[15] F. Avilés and L. A. Carlsson, "Analysis of the sandwich DCB specimen for debond characterization," Engineering Fracture Mechanics, vol. 75, no. 2, pp. 153-168, 2008.

[16] V. Vadakke and L. A. Carlsson, "Experimental investigation of compression failure of sandwich specimens with face/core debond," Composites Part B: Engineering, vol. 35, no. 6-8, pp. 583-590, 2004.
[17] ASTM D3039-08, Standard Test Method for Tensile Properties of Polymer Matrix Composite Materials, ASTM, West Conshohocken, PA, USA, 2008.

[18] ASTM D695-10, Standard Test Method for Compressive Properties of Rigid Plastics, ASTM, West Conshohocken, PA, USA, 2015.

[19] ASTM C393-62, Standard Test Method for Flexural Properties of Sandwich Constructions, ASTM, West Conshohocken, PA, USA, 2000.

[20] ASTM D. 5528-01, Standard Test Method for Mode I Interlaminar Fracture Toughness of Unidirectional Fiber-Reinforced Polymer Matrix Composites, ASTM, West Conshohocken, PA, USA, 2001.

[21] T. S. Gates, X. Su, F. Abdi, G. M. Odegard, and H. M. Herring, "Facesheet delamination of composite sandwich materials at cryogenic temperatures," Composites Science and Technology, vol. 66, no. 14, pp. 2423-2435, 2006.

[22] G. R. Irwin and J. A. Kies, "Critical energy rate analysis of fracture strength," Welding Journal Research Supplement, vol. 33, pp. 193-198, 1954.

[23] K. Mohan, Y. T. Hon, S. Idapalapati, and H. P. Seow, "Failure of sandwich beams consisting of alumina face sheet and aluminum foam core in bending," Materials Science and Engineering: A, vol. 409, no. 1-2, pp. 292-301, 2005. 